\title{
Precocious puberty due to a hypothalamic hamartoma in a patient surviving to late middle age
}

\author{
LIONEL WOLMAN AND G. V. BALMFORTH \\ From the Department of Neuropathology and Medical Unit, Royal Infirmary, Sheffield
}

Precocious puberty is considered to be present when gonadal function, which is adult in type and degree, is accompanied by secondary sex development, in the male or female, some years before this would normally be expected (Simpson, 1959). Seckel (1946) regarded genital maturation as precocious when it became apparent in boys before the age of 10 years and in girls before the age of 8 years. It is usually an idiopathic acceleration of normal puberty and is considerably more common in girls than in boys (Jolly, 1951). Identical features can result from involvement of the hypothalamus either directly or indirectly in disorders of adjacent structures, such as the pineal and upper brain-stem. Such cases are more common among boys than girls (Weinberger and Grant, 1941). Of the various pathological lesions affecting the hypothalamus, a well-defined group is the hamartoma occurring on the ventral aspect of the posterior hypothalamus. Over 30 cases have now been described in the literature and the majority of these have been reviewed recently by Schmidt, Hallervorden, and Spatz (1958). Most children developing the condition due to hypothalamic causes either die young or survive only till early adult life, being especially sensitive to operative procedures (Le Marquand and Russell, 1935). That reasonable longevity may be compatible with these growths is suggested by the family reported by Rush, Bilderback, Slocum, and Rogers (1937), in which sexual prococity was found in the father and two sons as well as in other members, and is confirmed by the following study of a patient who survived until the age of 62 years.

\section{CASE REPORT}

A.W., a woman aged 62 , developed rapidly during childhood. Menstruation began at the age of 7 , and by this time the breasts had become as large as her mother's. Growth ceased at the age of 9 when she measured $4 \mathrm{ft}$. $6 \frac{1}{2}$ in. and weighed $15 \mathrm{st}$. $6 \mathrm{lb}$. The periods, which were heavy, continued regularly at monthly intervals until the age of 21 . Thereafter, they were irregular until the menopause occurred in the early thirties. At about this time she began to shave regularly. Although married, she never became pregnant. Her father, a diabetic, died from heart disease. Her mother and seven siblings were all normal.

About one month before her sudden death she developed thirst, polyuria, lassitude, and loss of weight. She was found to be a strikingly short and obese woman weighing 15 stones. There were large dewlaps. The feet and hands were tiny. She had a beard but the hair was distributed normally elsewhere. Investigations included a fasting blood sugar level of $292 \mathrm{mg}$. $100 \mathrm{ml}$., urinary 17-ketosteroids of $4.7 \mathrm{mg}$. $/ 24 \mathrm{hr}$., 17-ketogenic steroids of $6.0 \mathrm{mg} . / 24 \mathrm{hr}$., and gonadotrophins of 54 mouse units/24 hours. The blood pressure was $190 / 100 \mathrm{~mm}$. Hg. There was a B.coli urinary tract infection. The diabetes mellitus was controlled with a 1,000 calorie diet. She collapsed and died a few minutes after the sudden onset of dyspnoea.

\section{POST-MORTEM FINDINGS}

The cause of death was a large pulmonary embolus blocking the bifurcation of the pulmonary artery. It had arisen from a deep vein thrombosis in the left external iliac vein. The heart weighed $305 \mathrm{~g}$. and showed left ventricular hypertrophy. The kidneys were mildly scarred. The uterus and ovaries were small and atrophic. The thyroid, pancreas, and adrenals appeared normal.

The brain (weight $990 \mathrm{~g}$.) was small with a normal convolutional pattern and slight bilateral frontal cortical atrophy. The mammillary bodies appeared enlarged when viewed from the ventral aspect of the brain (Fig. 1) but a closer inspection of the midline sagittal section revealed that they were both of normal size but attached to and covering them was a small firm white pedunculated mass measuring $1.5 \times 1 \times 1 \mathrm{~cm}$. The attachment of the nodule to the hypothalamus was by a broad base extending anteriorly on to the posterior part of the tuber cinereum more on the right than the left (Figs. 2 and 3). It had not produced any signs of compression or distortion of the neighbouring parts and the ventricular system was of normal size and shape without any displacement. The pituitary fossa appeared slightly enlarged but the gland was normal. The pineal gland showed no abnormality. 

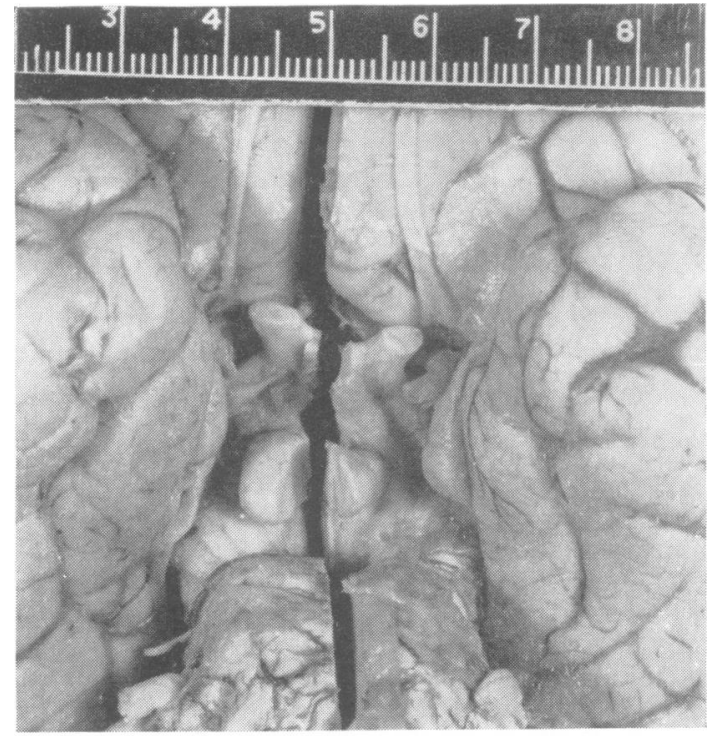

FIG. 1

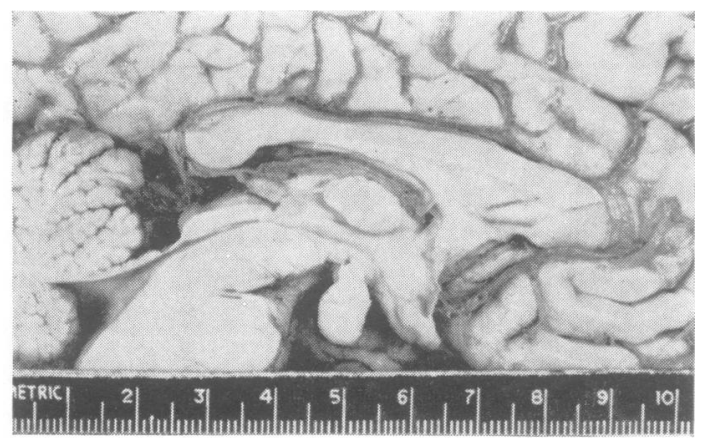

FIG. 2

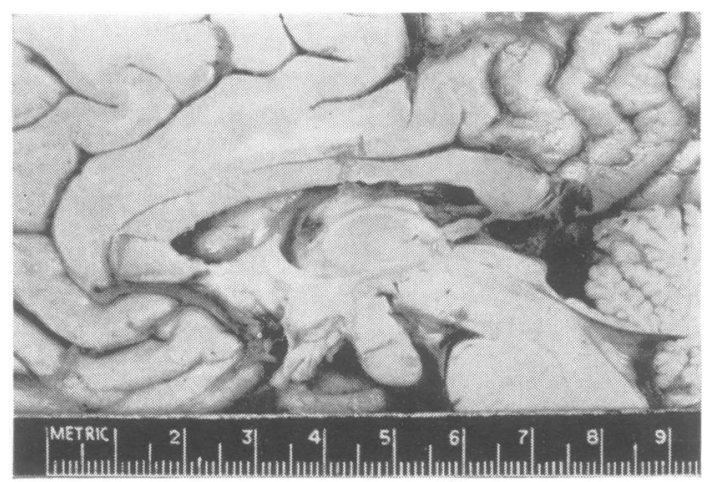

FIG. 3

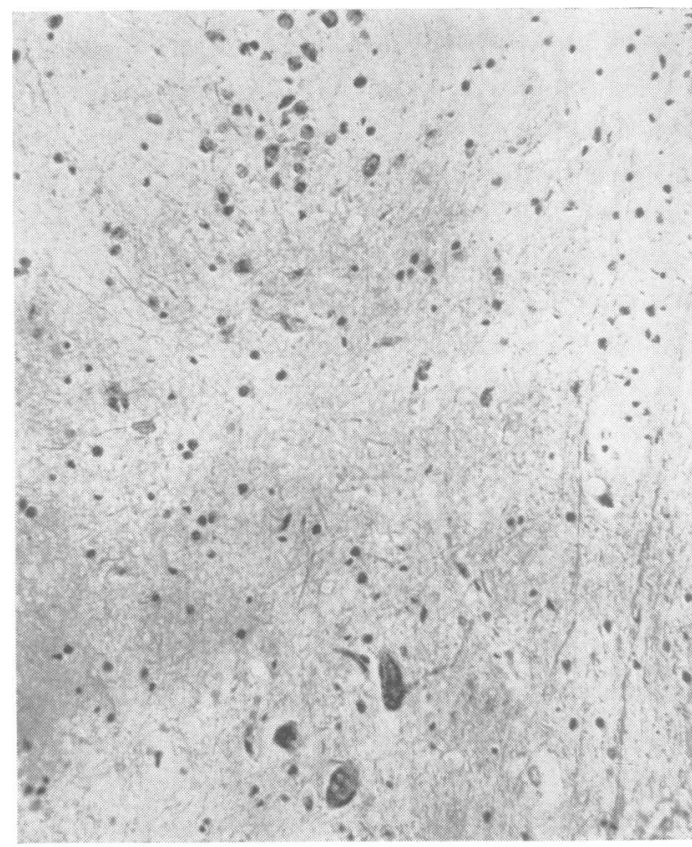

FIG. 4

FIG. 1. Ventral aspect of the brain showing nodulab enlargement of the mammillary bodies. The brain had been sectioned sagittally in the midline.

FIG. 2. Midline sagittal section of brain viewed from left showing hamartoma attached to a normal-sized right mammillary body and extending forwards on to the ventral surface of the tuber cinereum.

FIG. 3. Midline sagittal section of brain viewed from $\stackrel{\mathbb{}}{\unrhd}$ right showing hamartoma attached almost entirely to $\overrightarrow{\overrightarrow{\hat{O}}}$ normal-sized left mammillary body.

FIG. 4. Section of dorsal part of hamartoma showing $a$ 름 group of large nerve cells on the right adjacent to a cluster of small nerve cells. A band of nerve fibres can be seen extending across the upper part of the section and these were situated near the capsule of the mammillary body. Silver stain. $\times 150$.

FIG. 5. Section of central part of hamartoma showing a solitary nerve cell and widely separated nerve fibres. Silver stain. $\times 400$.

FIG. 6. Coronal section of left mammillary body with $\overline{\mathrm{N}}$ attached hamartoma showing nuclear masses of nerve cells separated by bundles of myelinated nerve fibres in the dorsal part of the malformation. Mallory's P.T.A.H. $\times 12.3$. 


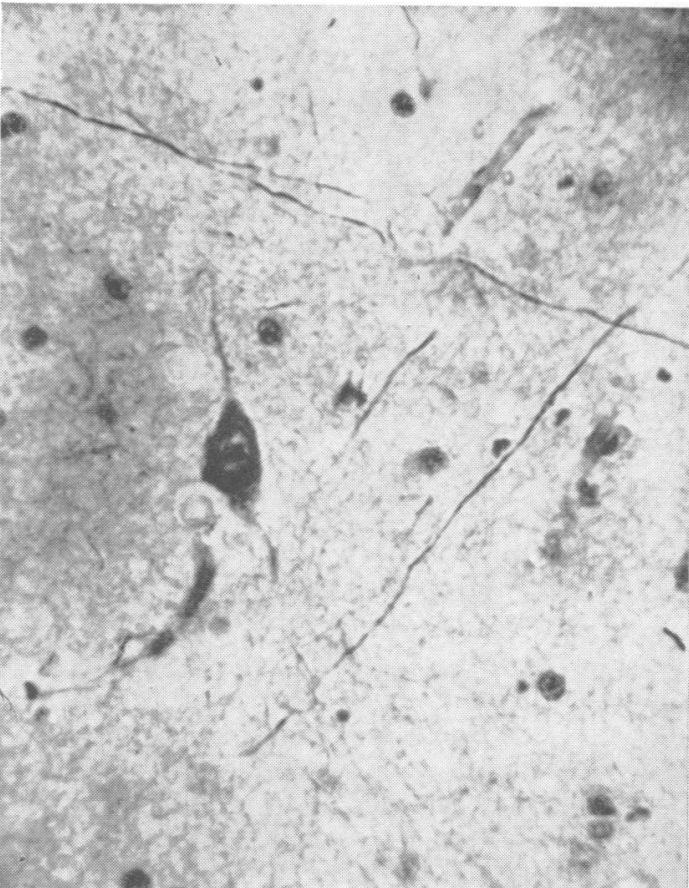

FIG. 5

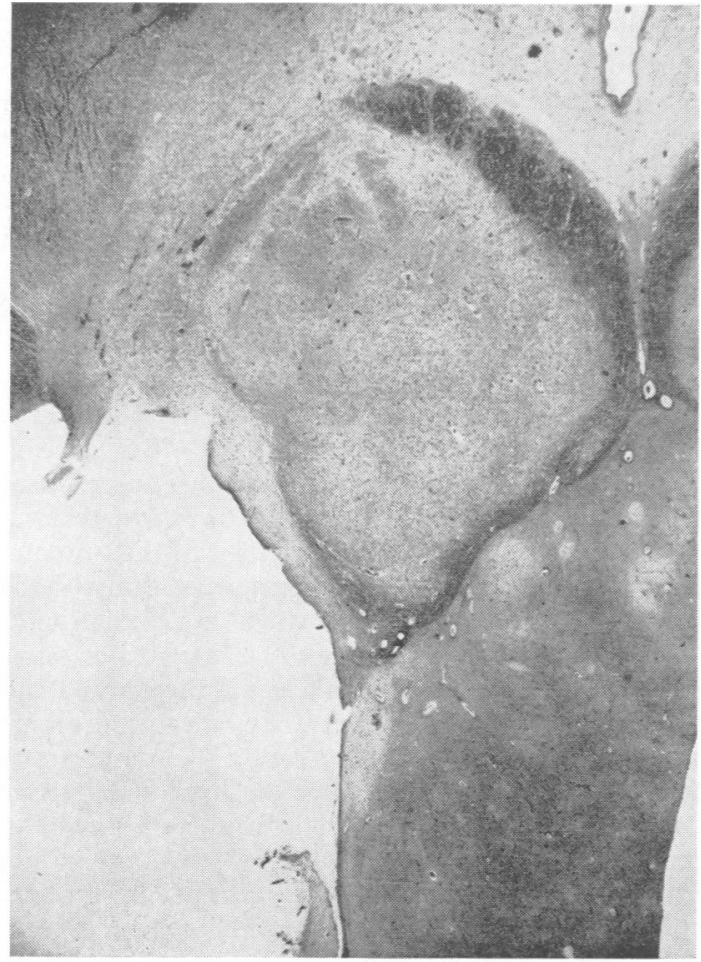

FIG. 6

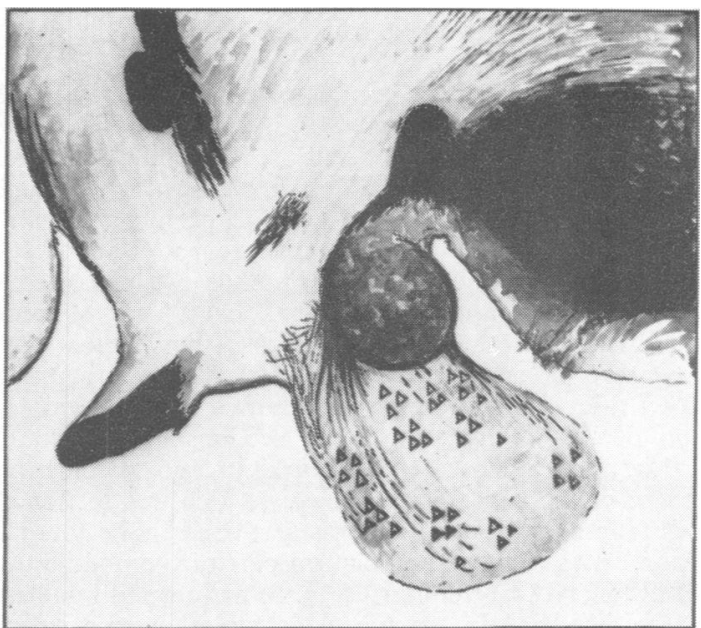

FIG. 7

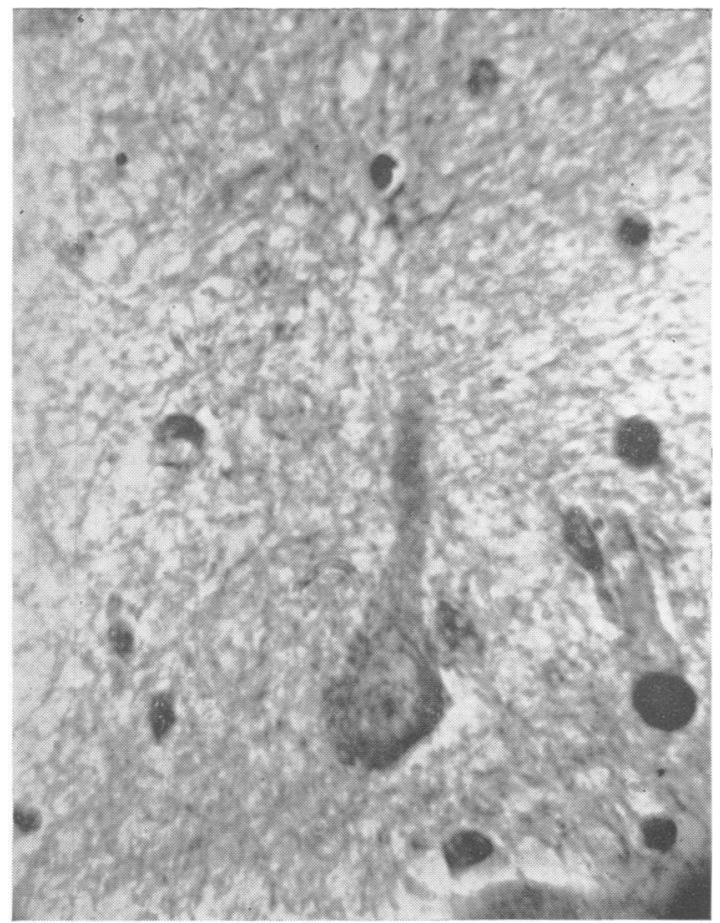

FIG. 8

FIG. 7. Diagrammatic representation of the connexions of the hamartoma with the right hypothalamus as seen in sagittal section. The triangles represent groups of nerve cells.

FIG. 8. Nerve cell from hamartoma containing neurosecretory material which is also distributed irregularly along its axone giving a beaded appearance.

Performic acid-alcian blue. $\times 820$. 
HISTOLOGICAL EXAMINATION

The nodule consisted of groups of nerve cells separated by a loose astroglial network in which were many myelinated nerve fibres and scanty interfascicular oligodendroglia. The glial fibres were most dense around perivascular spaces and around the periphery of the nodule where there were very many corpora amylacea. The pia arachnoid over the nodule was markedly thickened but appeared normal over the adjacent hypothalamus. Some of the groups of nerve cells were composed of small neurones while others were much larger (Fig. 4). A few nerve cells showed bullous vacuolation of their cytoplasm. Serial sections of the nodule and adjacent hypothalamus were examined to trace the course of the nerve fibres. The right side was sectioned sagittally and the left side was sectioned in the coronal plane. In the ventral and central part of the nodule the fibres tended to be solitary (Fig. 5) or in small bundles. These increased in size near the hypothalamus where large bands of nerve fibres occurred between the groups of nerve cells. Many of these fibres merged with the capsule of the mammillary body (Fig. 6) but anteriorly they extended into the area praemammillaris of the posterior hypothalamus and the tuber cinereum establishing connexions with the nucleus mammillo-infundibularis and the nucleus tuberis lateralis (Fig. 7).

Some evidence for the functional activity of these connexions was sought by staining sections by the Gomori and performic acid-alcian blue techniques for neurosecretory substance. A few scattered nerve cells and fibres contained granules of this material (Fig. 8).

The nuclei of the hypothalamus appeared of normal size and showed no degenerative changes. The pituitary contained chromophobe, eosinophils, and basophils in normal proportions. Many of the basophils were vacuolated. Both $\mathbf{R}$ and $\mathbf{S}$ mucoid basophil cells were demonstrated in normal numbers by the performic acid-alcian blue-P.A.S.-orange $G$ staining technique.

\section{DISCUSSION}

This hypothalamic nodule, composed of nerve cells resembling those in the tuber cinereum together with normal glial cells, showed no evidence of neoplasia and is regarded as a hamartoma.

All the cases reported in the literature show similar sites and histological appearances of the hamartomata which originate from the region of the tuber cinereum and extend caudally into the basal cistern. They are composed of nerve cells, both large and small, which may be arranged irregularly or in small groups. Occasionally they form a pseudo-cortical band similar to that of the entorhinal region or resemble those seen in the amygdaloid nucleus, while in some cases they are entirely absent (McCullagh, Rosenberg, and Norman, 1960). The glia is not usually conspicuous but may be so and ependymal cell nests may be present (van der Sar and Moffie, 1960). A retinal anlage was seen in the case described by Graber and Kersting (1955). The ${ }_{\mathbb{D}}$ fact that hamartomatous malformation of the $=$ hypothalamus may not be so uncommon is suggested कs by the work of Sherwin, Grassi, and Sommers (1962) who found miniature hamartomatous nodular 0 projections of the tuber cinereum in the posterolateral portion of the hypothalamus in $21 \%$ of 121 brains? carefully examined. Multiple endocrine abnormalities and neoplasms were significantly increased in these. cases.

Of the symptoms associated with hypothalamic hamartomata, pubertas praecox is the most striking and frequent. As many diverse types of tumour of $\frac{\overline{\bar{w}}}{\bar{n}}$ the hypothalamus have been reported associated $\overrightarrow{\widetilde{\sigma}}$ with precocious puberty (Morley, 1954), it is not $\varrho$ likely that the pathological type of growth is important but rather its effect on the hypothalamic $\vec{\circ}$ nerve cells and connexions. It thus seems likely that the fibre connexions of these hamartomas arew important in influencing the onset of precocious? puberty. Occasionally, however, the hamartoma has been discovered as a chance finding at necropsy in a previously normal and healthy individual, as ic the 19-year-old male negro described by Bedwelli and Lindenberg (1961), who attributed the absenge $\overrightarrow{\text { or }}$ of premature development to the lack of fibaeo connexions between the hamartoma and the tuber? cinereum. In three of the four cases described byc Schmidt et al. (1958) death occurred too early for pubertas praecox to have developed. This symptom. was not present in the 30-year-old patient described by Henschen (1955) in whom the hamartoma wats attached to one mammillary body, but as no histological details were given there may have been no tuberal connexions. Dabezies, Walsh, and Hayesō (1961) also described a patient without precocious puberty but with papilloedema. At operation the $\underset{\mathcal{Q}}{\mathbb{Q}}$ hamartoma was compressing the optic chiasma but $\vec{\overrightarrow{ }}$ its hypothalamic connexions were not established. $\frac{3}{3}$ In the two cases reported by Marcuse, Burger, and Salmon (1953) the absence of precocious puberty was attributed to the young age at death $(6$ months and 5 years) and possibly to the huge size of the tumours? which may have resulted in pressure atrophy of the hypothalamic centres rather than in stimulation.

The other main constituent of these hamartomasi is the nerve fibres. Most of these are myelinated and occur in small groups but they may form large bundles and tracts passing from the hamartoma through the tissue bridge into the hypothalamus as described by Richter (1951). In the boy aged 3 described by Driggs and Spatz (1939) and in the $N$ 22-month-old girl described by Bronstein, Luhan, $N$ and Mavrelis (1942) myelinated fibres were present but there was no passage between the hamartoma ${ }_{0}^{\omega}$ and the tuber cinereum. 
In the present case the nerve cells were arranged in nuclear masses of varying size which established fibre connexions with the capsule of the mammillary body and with the mammillo-infundibular nuclei and the tuberal nuclei in the premammillary area. The finding of small amounts of neurosecretory substance in a few of the nerve cells and fibres in the hamartoma provides some evidence of the functional significance of these connexions in view of the belief that neurosecretory material may play a role in the hypothalamic regulation of the gonadotrophic activity of the adenohypophysis (Árvay, Bölönyi, Balázsy, and Jakubecz, 1960). The demonstration that neurosecretory fibres penetrate the adeno-neurohypophysial contact surface and enter the pars tuberalis and pars distalis as well as ending on the walls of the plexus of the hypophysial portal vessels (Okamoto and Ihara, 1960) provides an antomical basis for this concept.

The importance of the mammillary region of the hypothalamus in the regulation of gonadotrophic secretion from the pituitary has been demonstrated experimentally in animals (De Groot and Harris, 1952; Sawyer and Robison, 1956) while the experimental production of hypothalamic lesions provides evidence of the role of both the anterior and posterior parts in gonadal control. Thus Krejci and Critchlow (1959) found that lesions in the amygdala and anterior hypothalamus in immature female rats were associated with increased uterine weight whereas lesions of the posterior hypothalamus, thalamus, septum, and internal capsule were ineffective. Bogdanove and Schoen (1959) also found that lesions of the anterior hypothalamus were associated with ovarian follicular growth and uterine hypertrophy whereas lesions destroying the arcuate nucleus in the posterior tuberal region resulted in luteinization as well. Similar results were obtained by Donovan and van der Werff ten Bosch (1959) and were confirmed by Elwers and Critchlow (1960). They support the idea of an anterior hypothalamic mechanism inhibiting gonadotrophic secretion.

In the case of more posteriorly situated lesions, Bustamante (1942) found that in young rabbits electrolytic destruction of the tuber cinereum produced disturbances of sexual development whereas lesions of the mammillary bodies did not. In the rat, Gellert and Ganong (1960) produced electrolytic lesions involving the arcuate nucleus in the posterior tuberal region of the hypothalamus. Significantly earlier maturation resulted than in the unoperated controls while lesions in the anterior hypothalamus, mammillary body, hippocampus, thalamus, and cortex were ineffective. Corbin and Schottelius $(1960,1961)$ have reported that posterior hypothalamic lesions lead to delayed puberty and sexual retardation in immature female rats. In the dog, lesions of the posterior median eminence of the hypothalamus were associated with atrophy of the testis and prostate (Ganong, Fredrickson, and Hume, 1955; Daily and Ganong, 1958).

If the tuber cinereum regulates sexual maturation, as these experiments suggest, it could do so in one of three ways. It could control gonadotrophic activity by fibre connexions with the adenohypophysis, or alternatively it could use a humoral mechanism by neurosecretion although, as in this case, increased gonadotrophic excretion has never been demonstrated. The third possibility is by a direct descending diencephalic-spinal sympathetic pathway to the gonads (Krücke, 1949; Nowakowski, 1950). Thus a hamartoma containing nerve cells connected with the tuber cinereum might lead to the development of precocious puberty by excess neuronal activity possibly augmented by lack of other neural inhibitory control. Its function could be likened to the action of an overdrive mechanism.

\section{SUMMARY}

Precocious puberty in a girl, who survived till the age of 62 , when death occurred from pulmonary embolus, is described.

At necropsy a hypothalamic hamartoma was found attached to the mammillary bodies and tuber cinereum but it had not become large enough to damage or exert any pressure effects on neighbouring structures.

Microscopically the hamartoma contained groups of nerve cells and bundles of myelinated nerve fibres which connected with the capsule of the mammillary bodies and the tuberal nuclei and nuclei mammilloinfundibularis of the premammillary area. Neurosecretory substance was found in a few of the nerve cells and fibres of the hamartoma.

Of the cases of hypothalamic hamartoma reported in the literature some were found at necropsy in normal adults and in these hypothalamic connexions were absent or doubtful. Of the ones associated with precocious puberty, definite fibre connexions with the hypothalamus were demonstrated.

The effects on gonadal function of experimental lesions in this part of the hypothalamus of animals are summarized and correlated with the anatomical findings in the case. It is concluded that the hamartoma acts as an overdrive to the posterior hypothalamic area, using a neurosecretory mechanism.

We wish to acknowledge the assistance of Dr. F. D. Rosenthal, under whose care this patient was admitted, 
for the clinical details, and of Dr. S. M. Smout and Dr. A. G. Ackerley for details of the necropsy and for submitting the specimen from Leicester General Hospital.

\section{REFERENCES}

Árvay, A., Bölönyi, F., Balázsy, L., and Jakubecz, S. (1960). Acta anat. (Basel), 40, 256.

Bedwell, S. F., and Lindenberg, R. (1961). J. Neuropath. exp. Neurol. 20, 219.

Bogdanove, E. M., and Schoen, H. C. (1959). Proc. Soc. exp. Biol. $(N . Y), 100,$.

Bronstein, I. P., Luhan, J. A., and Mavrelis, W. B. (1942). Amer. J. Dis. Child., 64, 211.

Bustamante, M. (1942). Arch. Psychiat. Nervenkr., 115, 419.

Corbin, A., and Schottelius, B. A. (1960). Proc. Soc. exp. Biol. (N.Y.), 103, 208.

- , (1961). Ibid., 106, 841.

Dabezies, O. H., Walsh, F. B., and Hayes, G. J. (1961). Arch. Ophthal. (Chic.), 65, 174.

Daily, W. J. R., and Ganong, W. F. (1958). Endocrinology, 62, 442.

De Groot, J., and Harris, G. W. (1952). Ciba Foundation Colloq Endocrinology, 4, 103.

Donovan, B. T., and van der Werff ten Bosch, J. J. (1959). J. Physiol. (Lond.), 147, 78.

Driggs, M., and Spatz, H. (1939). Virchows Arch. path. Anat., 305, 567.

Elwers, M., and Critchlow, V. (1960). Amer. J. Physiol., 198, 381.

Ganong, W. F., Fredrickson, D. S., and Hume, D. M. (1955). Endocrinology, 57, 355.
Gellert, R. J., Ganong, W. F. (1960). Acta endocr. (Kbh.), 33, 569. Graber, H., and Kersting, G. (1955). Dtsch. Z. Nervenheilk., 173, 1 \ Henschen, F. (1955). In Handbuch der speziellen pathologischen Anatomie und Histologie, edited by $\mathrm{O}$. Lubarsch, F. Henke R. Rössle, vol. 13, Part III, p. 703. Springer, Berlin. Jolly, H. (1951). Proc. roy. Soc. Med., 44, 459.

Krejci, M. E., and Critchlow, V. (1959). Anat. Rec., 133, 300.

Krücke, W. (1949). Dtsch. Z. Nervenheilk., 160, 196.

Le Marquand, H. S., and Russell, D. S. (1935). Royal Berks Hosp Rep., 1934-1935, 3, 31.

Marcuse, P. M., Burger, R. A., and Salmon, G. W. (1953). J. Pediat. 43,301

McCullagh, E. P., Rosenberg, H. S., and Norman, N. (19€0). J. Clink Endocr., 20, 1286.

Morley, T. P. (1954). Ibid., 14, 1.

Nowakowski, H. (1950). Acta neuroveg. (Wien), 1, 13.

Okamoto, S., and Ihara, Y. (1960) Anat. Rec., 137, 485.

Richter, R. B. (1951). J. Neuropath. exp. Neurol., 10, 368.

Rush, P. H., Bilderback, J. B., Slocum, D., and Rogers, A. (1937) Endocrinology, 21, 404.

Sar, A. van der, and Moffie, D. (1960), Acta Psychiat. scand., 35, 345ळ

Sawyer, C. H., and Robison, B. (1956). J. Clin. Endocr., 16, 914.

Schmidt, E., Hallervorden, J., Spatz, H. (1958). Dtsch.Z. Nervenheilk. ڤొల $177,235$.

Seckel, H. P. G. (1946). Med. Clin. N. Amer., 30, 183.

Sherwin, R. P., Grassi, J. E., and Sommers, S. C. (1962). Lab. Invest: $11,89$.

Simpson, S. L. (1959). Major Endocrine Disorders, 3rd ed., p. 376 Oxford University Press, London.

Weinberger, L. M., and Grant, F. C. (1941). Arch. intern. Med.马 67,762 . 